\title{
Presence Effects in Virtual Reality Based on User Characteristics: Attention, Enjoyment, and Memory
}

\author{
Si Jung Kim ${ }^{1}$, Teemu H. Laine ${ }^{2}(\mathbb{D})$ and Hae Jung Suk ${ }^{2, *(\mathbb{D}}$ \\ 1 College of Engineering, University of Nevada Las Vegas, Las Vegas, NV 89154, USA; sj.kim@unlv.edu \\ 2 Department of Digital Media, Ajou University, \#206 Worldcup-ro, Yeongtong-gu, Suwon 16499, Korea; \\ teemu@ubilife.net \\ * Correspondence: dbdip@ajou.ac.kr
}

Citation: Kim, S.J.; Laine, T.H.; Suk, H.J. Presence Effects in Virtual Reality Based on User Characteristics: Attention, Enjoyment, and Memory. Electronics 2021, 10, 1051. https:// doi.org/10.3390/electronics10091051

Academic Editors: Osvaldo Gervasi and Javid Taheri

Received: 18 February 2021

Accepted: 26 April 2021

Published: 29 April 2021

Publisher's Note: MDPI stays neutral with regard to jurisdictional claims in published maps and institutional affiliations.

Copyright: (c) 2021 by the authors. Licensee MDPI, Basel, Switzerland. This article is an open access article distributed under the terms and conditions of the Creative Commons Attribution (CC BY) license (https:// creativecommons.org/licenses/by/ $4.0 /)$.

\begin{abstract}
Presence refers to the emotional state of users where their motivation for thinking and acting arises based on the perception of the entities in a virtual world. The immersion level of users can vary when they interact with different media content, which may result in different levels of presence especially in a virtual reality (VR) environment. This study investigates how user characteristics, such as gender, immersion level, and emotional valence on $\mathrm{VR}$, are related to the three elements of presence effects (attention, enjoyment, and memory). A VR story was created and used as an immersive stimulus in an experiment, which was presented through a head-mounted display (HMD) equipped with an eye tracker that collected the participants' eye gaze data during the experiment. A total of 53 university students (26 females, 27 males), with an age range from 20 to 29 years old (mean 23.8), participated in the experiment. A set of pre- and post-questionnaires were used as a subjective measure to support the evidence of relationships among the presence effects and user characteristics. The results showed that user characteristics, such as gender, immersion level, and emotional valence, affected their level of presence, however, there is no evidence that attention is associated with enjoyment or memory.
\end{abstract}

Keywords: virtual reality; presence effects; user characteristics; immersion; eye-tracking

\section{Introduction}

The concept of virtual reality (VR), a term first coined in 1987 by Jaron Lanier [1], has been applied in art and photography for many years, using panoramic layouts or optical illusions that make people feel they are seeing a real scene, bringing about realism, an on-stage, and three-dimensional (3D) sense. From the stereoscopic viewers in the midnineteenth century to the latest head-mounted displays (HMD) with embedded sensors, the purpose of these VR technologies-giving perfect depth, perfect solidity, and perfect space to human eyes-has not changed [2]. In 1968, Ivan Sutherland and his student Bob Sproull created the first HMD-The Sword of Damocles-that was connected to a computer and not to a camera [3]. Since then, various attempts have been made to experience artificial reality [4]. The great effort put into VR technology development recently is expected to lead to more experimentation and research threads to explore.

VR enables the user to experience life-like events that may evoke the feeling of presence [5]; 'being there' that comprises psychological responses and states that occur in a virtual space [5-9]. Marvin Minsky uses the term "telepresence" to define the user experience as a phenomenon wherein the user feels physically present in an imaginary space through feedback he receives from the machine using teleoperation technology [10]. This idea of presence was launched in earnest by Sheridan and Furness in 1992 with the publication of the journal "Presence: Teleoperators and Virtual Environments" [11], while Steuer argues that presence leads to a natural perception of the environment [12]. Slater and Usoh define presence as a degree of confidence that one is in a place other than where one is, i.e., that the user has left the real world and is in a virtual environment [13]. Aligned 
with this, Witmer and Singer define presence as a subjective experience in which the user feels he or she is physically in another place or environment [14]. Lombard et al. define presence as a psychological state and the subjective perception state [15]. The efficiency of presence can be summarized as concentration, arousal, and pleasure because of immersion and memory [16]. Based on the aforementioned definitions of presence, we propose the following definition for presence to be used in this study:

"Presence refers to the emotional state of users where their motivation for think-

ing and acting arises based on the perception of the entities in a virtual world."

Immersion is a crucial implicit condition of presence in many of the aforementioned definitions, and VR is a medium that has been shown to make the user immersed in a story, regardless of the user's characteristics [17]. By observing the user's behaviour and measuring their presence effects in VR, it could be shown to what extent the user's immersion is dependent on the media format.

User characteristics can be classified based on the level of immersion in prior media experiences [18] and the motivation of this research is to seek an answer how classified user characteristics are related to presence effects influenced by the levels of attention, enjoyment, and memory. The rationale for the research is that the level of user experience is related to the level of presence in VR. The research hypothesis formed in this study is that presence effects would be different depending on the user's characteristics, especially based on their immersion level. Figure 1 shows the elements of user characteristics; this study focuses on whether gender, immersion level, and emotional valence (i.e., positive and negative emotions) on VR are related to the presence effects. Moreover, we set young Korean adults (university students) as the target group for the experiment.

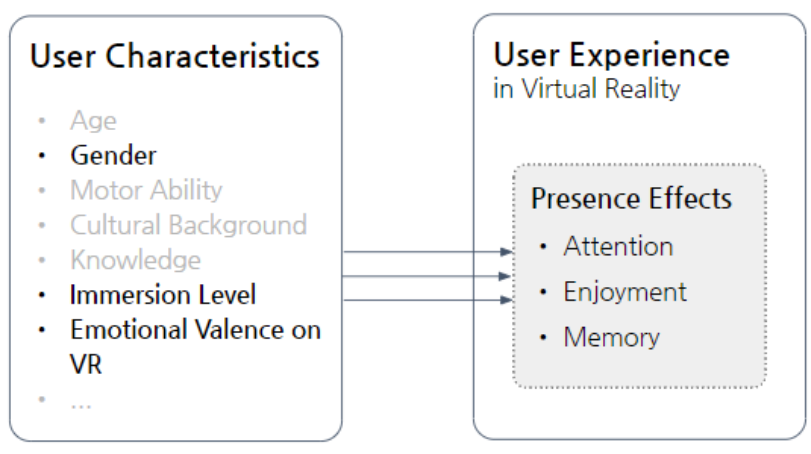

Figure 1. The concept of the user characteristics and presence effects that this study explores. The user characteristics that are not part of this study are grayed out.

\section{Background}

Coelho et al. [6] presented two extreme perspectives of presence in a VR environment: the rationalist and the psychological or ecological. The rationalist perspective suggests that a VR system is composed of a set of machines that communicate and thereby produce a VR environment, and the presence is achieved when the VR medium disappears from user's conscious attention, thus enabling suspension of disbelief. The psychological or ecological perspective, on the other hand, views VR as a neuropsychological phenomenon that is largely dependent on the user's biological and cultural properties. Following these perspectives, our definition of presence shown above is somewhere between these two extreme perspectives, with an inclination toward the psychological perspective.

Presence in virtual reality has been shown to be a potential catalyst for various effects on users and their behaviour [5,7,19-21]. These effects are referred to as presence effects and they have been shown to be associated with media characteristics and user characteristics [18]. Heeter found in his research that the higher the presence, the higher the pleasure [7]. The findings of Tussyadiah et al. [21] showed three important effects of presence through an empirical study on VR tourism content. First, presence increases enjoyment of VR experiences. Second, the heightened feeling of being there results in 
stronger liking of the destination. Third, positive attitude change leads to a higher level of visitation intention. In another study, Jung and Ahn [19] explored the use of VR for knowledge and skill training. Their results revealed that while different educational media (traditional lecture, a computer, VR, and a controller, and VR with wearable device) had no significantly different effects on acquiring knowledge, skill training was more effective in the virtual world. The effect was especially significant in VR with a wearable device, thus indicating the importance of natural interaction in creation of presence. Moreover, it has been found that presence can improve the user's memory of media content [20], thus implying that presence effects are related to short term memory performance while experiencing media. Cummings and Bailenson found that presence effects are not inherited from the immersive media itself [22].

Meanwhile, there is plenty of evidence that shows user characteristics as the variables in media use [18,23-25]. Findings in the study of Thorens et al. show that user characteristics determine how easy it is to dive into media presented on the internet and how hard it is to stop [25]. In another study, Kim et al. [26] surveyed the use of social media among college students, discovering that the participants' class level, disciplines and gender affect the use of social media platforms. Other similar studies on the effects of user characteristics on social media have been conducted $[27,28]$. Thus, based on our literature search, most of the previous studies at the intersection of user characteristics and media focused on the internet or social media use, or on the psychological analysis regarding user characteristic and presence.

Only a few studies have been conducted with regards to the relationships between presence effects and user characteristics [18,23,24]. For example, De Leo et al. [24] found a significant relationship between user characteristics and sense of presence in an online VR environment where distributed teams are trained. In their research, it was concluded that users who have knowledge about virtual environments and experience with gaming environments report a higher sense of presence, thus indicating that they will likely benefit more from online virtual training. In another study, Bulu [23] investigated and confirmed the relationship among three types of presence, including place presence, social presence, and co-presence in virtual worlds. The study also revealed that all of the three presence effects affect the user satisfaction, with the place presence having the strongest effect. Additionally, the study found that immersive tendencies of the students were related to the participants' place and co-presence but not to their social presence. Finally, Baños et al., [18] revealed that user characteristics that affect presence effects are various, including age, gender, cultural variables, users' perceptual, cognitive, motor abilities, prior experience with mediated experiences, willingness to suspend disbelief, and personality differences. As user-centred content is an important topic in media, it is meaningful to study the interrelationship between the characteristics of users and the advantages of virtual reality presence.

\section{Research Design}

Two research questions are formed as follows:

- $\quad$ RQ1. To what extent do the user's level of immersion in prior media experiences and the emotional valence on VR affect the presence effects such as attention, enjoyment, and memory in VR?

- RQ2. To what extent does the user's gender affect the presence effects in VR?

We applied a two-factor within subject design which includes individual experiences in media and VR, and gender (male and female). A pre-questionnaire, as shown in Appendix A, was made for investigating user characteristics. We used an eye-tracking system with a short VR story to observe the differences in visual attention among the groups that were formed based on the results of the pre-questionnaire. Finally, enjoyment and memory, as presence effects, were evaluated with a post-questionnaire after experiencing the VR story. The approach used in this research is a lab-based empirical study in which all participants experienced the VR story and then shared their experiences. Figure 2 depicts 
an overview of the study, which has a total of four steps: a pre-questionnaire, the VR Story experience that consist of four levels of transitions, a post-questionnaire, and data analysis. In the following sections, we present the experiment design in detail.

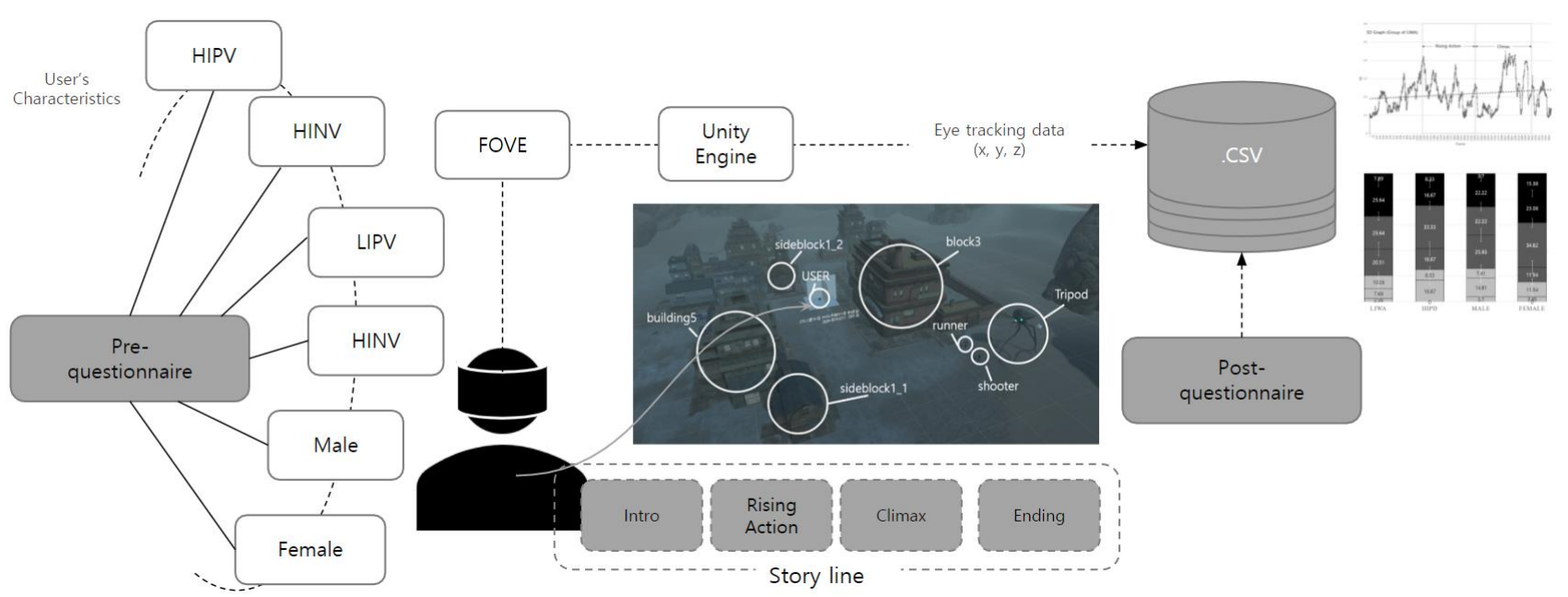

Figure 2. An overview of the study.

\subsection{Participants}

According to the central limit theorem (CLT) [29], a minimum of 30 participants should be recruited for an experiment. In total, we recruited 53 Korean university student participants (27 males, 26 females) with ages ranging between 20 and 29 (mean: 23.8) through both online and offline advertisements. Before the experiment started, the participants were informed about the ethical aspects of the experiment and about their right to stop the experiment should they wish to do so. They were also told about the types of data collection instruments that the experiment used, after which we asked them to provide an informed consent to collect their data for research purposes.

\subsection{Questionnaires}

\subsubsection{Pre-Questionnaire}

The pre-questionnaire (see Appendix A) consisted of six questions comprising demographic information and 29 self-evaluation statements. These statements were designed after the guidelines proposed by Watts and Stenner [30] and influenced by the presencerelated questionnaire developed by Witmer and Singer [14]. These questions were used to classify the participants according to their characteristics in media use. The questions were divided into two categories to decide each participant's immersion level in media and positive or negative valence toward VR, respectively. The emotional positive or negative valence can be a motive for involvement in a virtual environment when one experiences a scene. For example, to decide the level of immersion in general, the participants were given statements such as: '(Pre-Q.3) I easily become deeply involved in movies or TV dramas', '(Pre-Q.4) I focus on a movie, so I don't recognize something occurs around me', '(Pre-Q.6) I feel like I'm one of the athletes when watching a sports', '(Pre-Q.7) I feel fear from an incident in a TV drama or a movie'. To decide whether a subject has a positive or negative valence in VR, the participants were presented statements such as: '(Pre-Q.11) I'm not afraid of being immersed in VR', '(Pre-Q.13) VR provides a life-like fantasy', '(Pre-Q.15) We need a strict rule on a violent VR content', (Pre-Q.23) VR is a new opportunity to extend our experience', '(Pre-Q.27) VR is a kind of burden for me.' The participants answered the statements using a Likert scale from one to seven. 


\subsubsection{Post-Questionnaire}

A post-questionnaire (see Appendix A) was designed based on the literature review described in the introduction in this paper that concluded that presence as immersion includes a psychological component and the psychological state of a participant is best measured via subject self-report [15]. In order to measure the levels of enjoyment and memory, the participants evaluated these aspects from one to seven on a Likert scale after experiencing the VR story (see next section), and answered a quiz about what they had seen in VR scenes.

\subsection{VR Story (Stimulus)}

A piece of 60-s-long footage of an animated VR story was created as a stimulus for the experiment. Table 1 shows the overall structure of the VR story that is composed of four phases: Intro, Rising Action, Climax, and End.

Table 1. An overall plot of the virtual reality (VR) story.

\section{Intro: Frames $\mathbf{0 - 1 1 5 0}$}

- A phrase of information appears in front, and no objects are visible yet.

- The phrase disappears, and the view is changed to the animation scene.

- A soldier tagged 'back' runs from behind as the scene starts.

- The soldier runs out heading toward the buildings.

- A meteorite falls from the sky.

\section{Rising Action: Frames 1150-2300}

- The soldier stops in front.

- The meteorite is falling ahead.

- Two soldiers run out of the building on the left.

\section{Climax: Frames 2300-3400}

- An alien appears from 'buildings3' on the left.

- A soldier starts shooting the alien.

- The alien turns around and comes to the user in front while the soldiers flee from every direction.

\section{Ending: Frames $\mathbf{3 4 0 0 - 3 7 8 0}$}

- The alien stops moving and stares at the user in front.

- The ending phrase appears, and the content ends.

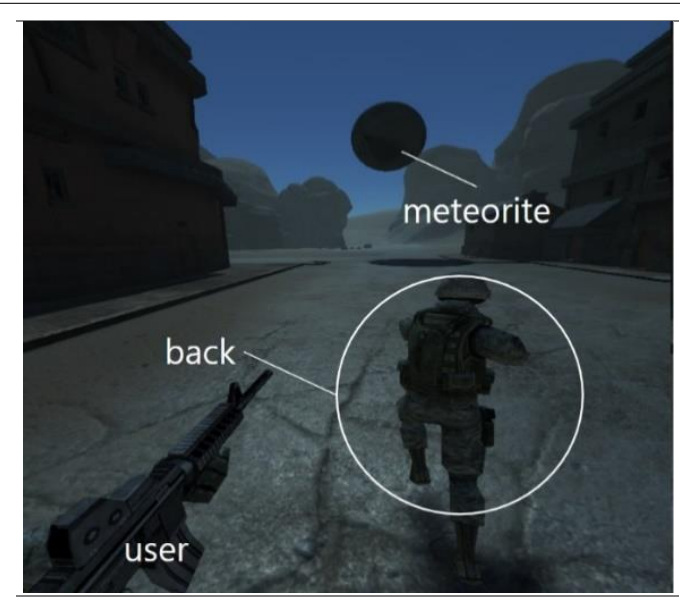

(2) Rising Action: A soldier 'back' appears in the user's sight.

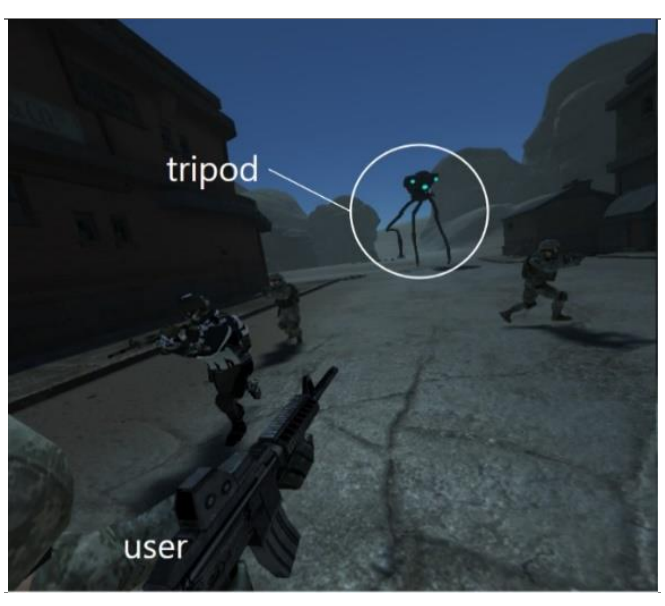

(3) Climax: The alien 'tripod' walked out heading to the user.

The VR story is a first-person shooter (FPS) game style animation, designed to enable the user to see seven different virtual objects shown in Figure 3. As seen in the figure, there 
are buildings and characters (soldiers) running ahead. The virtual environment and the assets including 3D objects and audio clips were utilized from the Unity Asset Store.

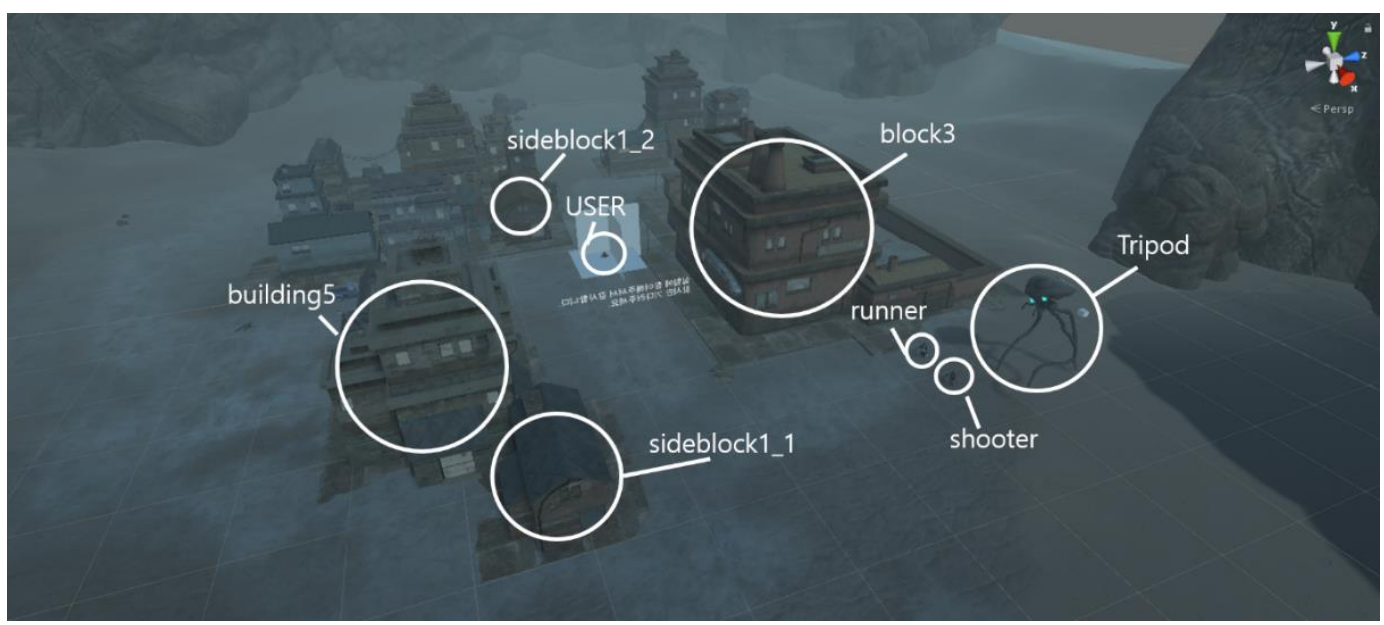

Figure 3. A snapshot of the VR environment of the story. The user sees the ending phrase in the center of the view. 'Thank you for your participation. Please wait until the experiment ends.'

\subsection{Expiremental Setup and Procedure}

The FOVE HMD with an eye tracker was used as the equipment to present the stimulus while collecting eye movement data. FOVE is equipped with eye-tracking technology that can record the user's orientation and position data as three-dimensional vectors of $x, y$, and $z$ [31]. It records eye gaze data of both the left and right eyes. Tare orientation and tare position of the device match the position of different users' foci and calibrate to users with physically different characteristics to optimize the eye tracker to their eyeballs (see FOVE Config Tool in Figure 4). The user plays the content after familiarizing themselves with the device. Figure 5 is a snapshot of the experimental setup showing the calibration of the FOVE HMD.

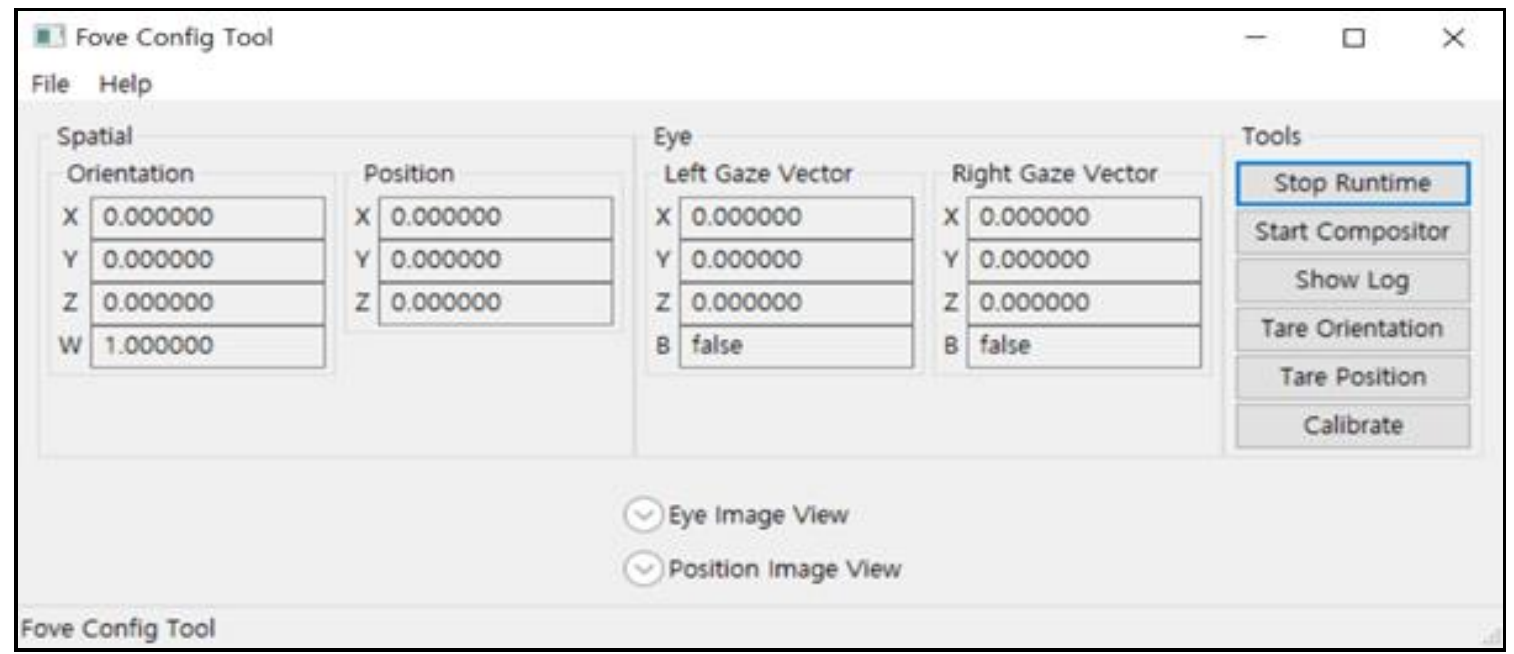

Figure 4. FOVE configuration total displaying device and target transform of eye tracking. 


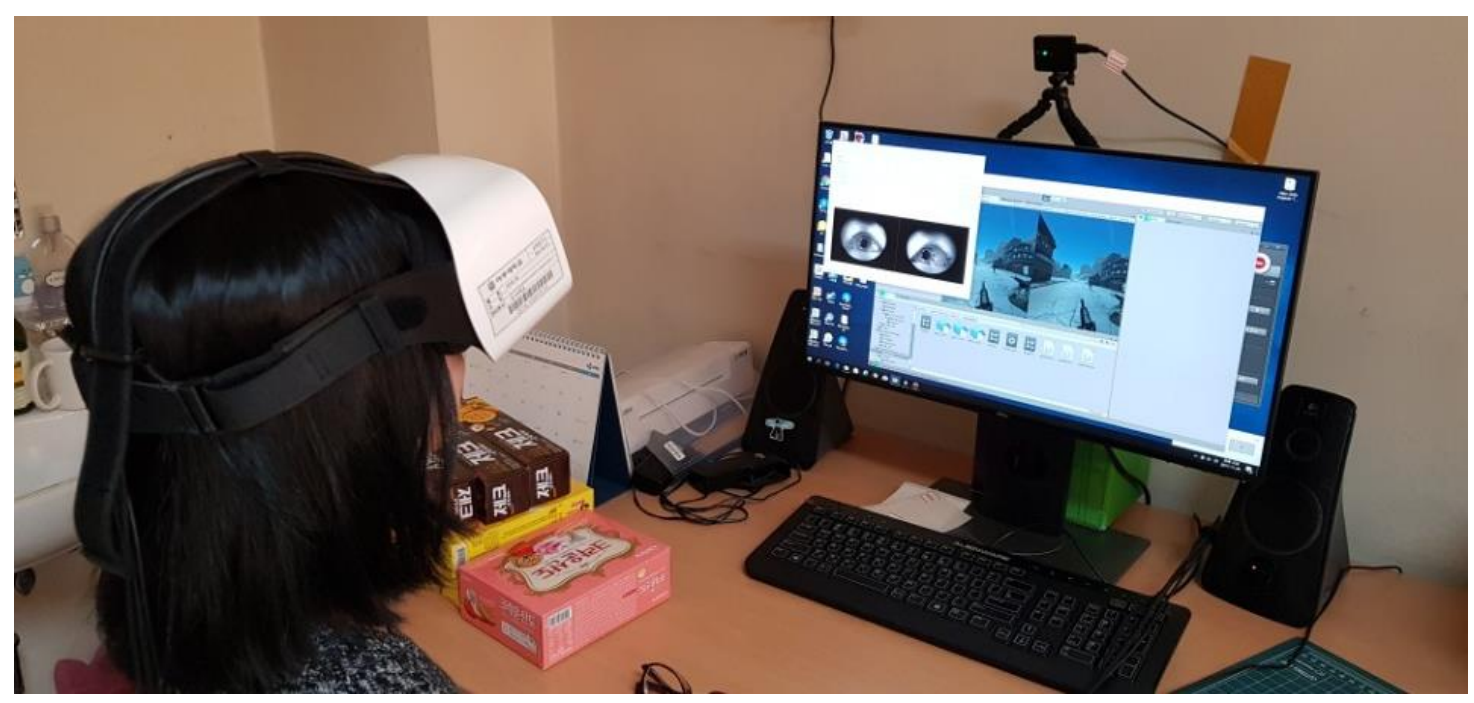

Figure 5. A snapshot of the experimental setup - a moment that calibrates the FOVE head-mounted display (HMD).

The participants took part in the experiment one by one. After they gave informed consent (see Section 3.1), the procedure and what they needed to do were explained. They were then asked to sit in a designated chair and put the FOVE HMD on, after which the Tare Orientation and Tare Position functions were adjusted to the position and angle. After the adjustment procedure, the device calibrated and optimized the subject's gaze and eye tracking. The participants then watched the VR story, removed the FOVE HMD, and answered the post-questionnaire. At the end of the experiment the participants were rewarded with a snack.

\subsection{Data Analysis}

Data analysis was conducted based on the two sets of data that were collected during the experiment: (1) eye tracking and (2) self-reported data through pre- and postquestionnaires. Eye tracking data were used to find out what objects the participants watched during their experience, which is a typical data gathering method in eye tracking research [31-33]. The questionnaires were used to know subjective opinions of the participants' individual experience.

Once the data were collected, we pre-processed them, which resulted in removal of one participant's data due to their failure to follow the instructions. The questionnaire answers were transformed into spreadsheet documents and organized for statistical analysis. During preprocessing, we also extracted the $x$-axis data of the participants' right eyes. The $y$-axis and z-axis data were intentionally omitted because they were deemed to be irrelevant as we were interested in analyzing only the participants' horizontal eye movements. This choice was made because the VR story content was largely horizontal, i.e., nearly all contents were placed within the same y-axis region.

The pre- and post-questionnaire data were analyzed by descriptive statistics, including the mean and standard deviation. Descriptive statistics were also used to analyze the eye tracking data; the results of this analysis were then visualized to inspect whether differences exist between gender groups and different user characteristic groups that were identified based on the pre-questionnaire answers. Additionally, we used raycasting in Unity to detect which objects the participants were looking at in each frame, and computed the mean number of hits for each object.

\section{Results}

A total of 53 university students, 27 males and 26 females, participated in the experiment. Their ages ranged from 20 to 29 (mean: 23.8, standard deviation: 2.3). Table 2 is the summary of the participants. 
Table 2. The numbers of participants in gender groups.

\begin{tabular}{ccccc}
\hline Groups & Number of Participants & Age Range & Mean & SD \\
\hline Male & 27 & $22-28$ & 24.2 & 1.9 \\
\hline Female & 26 & $20-29$ & 23.4 & 2.8 \\
\hline Total & 53 & $20-29$ & 23.8 & 2.4 \\
\hline
\end{tabular}

\subsection{User Analysis}

The participants were categorized into the four groups as shown in Table 2 based on their level of immersion and positive or negative valence in VR with appreciation or depreciation of new technologies. Each participant's answers were simply added as scores in each category, and the average of the participant's scores was compared to those of the other participants. High and low immersion levels were evaluated, then the means of positive or negative valence in VR were compared after. As a result, we found three types of user groups; high immersion group with positive valence (HIPV), low immersion group with positive valence (LIPV), and low immersion group with negative valence (LINV). High immersion with negative valence (HIPV) was not found among the participants. The participants in HIPV are deeply immersed when they are watching TV or movies, and they believe VR could make people have diverse experiences through an extended sense. The participants in LIPV have a low immersion level, but still they enjoy and appreciate new technologies. The participants in LINV have a low immersion level like those in LIPV, but they have many concerns about being in a virtual world and the society with unverified new technologies. Table 3 shows the distribution of the four groups identified and interestingly, no one was identified as LINV.

Table 3. The definition of participants groups.

\begin{tabular}{ccc}
\hline Groups & \multicolumn{1}{c}{ Definition } & Number of Participants \\
\hline HIPV & $\begin{array}{c}\text { The users in this group have the tendency of } \\
\text { high immersion in traditional media use and } \\
\text { positive valence in VR. }\end{array}$ & 39 \\
\hline LIPV & $\begin{array}{c}\text { The users in this group have the tendency of } \\
\text { low immersion in traditional media use but } \\
\text { positive valence in VR. }\end{array}$ & 2 \\
\hline HINV & $\begin{array}{l}\text { The users in this group have the tendency of } \\
\text { high immersion in traditional media use but } \\
\text { negative valence in VR. }\end{array}$ & 0 \\
\hline LINV & $\begin{array}{l}\text { The users in this group have the tendency of } \\
\text { low immersion in traditional media use and } \\
\text { negative valence in VR. }\end{array}$ & \\
\hline
\end{tabular}

As a result of the pre-questionnaire, out of 53 participants, 12 were assigned to HIPV, 39 to LIPV, and 2 to LINV. In addition, the data were analyzed in terms of gender. The distribution of genders of the participants in the three groups is shown in Table 4. Overall, two participants in the LIPV group were eliminated from the eye-gaze data results due to lack of data for statistical analysis, but they were included in the gender analysis.

Table 4. The gender distributions between the groups.

\begin{tabular}{cccc}
\hline Groups & Male & Female & Total \\
\hline HIPV & 1 & 11 & 12 \\
\hline LIPV & 25 & 14 & 39 \\
\hline HINV & 1 & 1 & 2 \\
\hline
\end{tabular}




\subsection{Eye-Gaze Data}

Selective attention, along with perceptual fidelity and other sensory factors, affects how much presence is reported [14]. Eye movement data of the participants' right eye (slightly different with their left eye but not significant for this analysis) were analyzed for observing their attention, then the average value of both eye gaze directions was calculated for each frame. By calculating the standard deviation (SD) using these averages of data from the subjects in each group, it is possible to grasp how much the participants' eye gaze deviated in each frame. In the Unity engine, 1 unit of grid corresponds to $1 \mathrm{~m}$ in the real world, so the scale of the SD shows how much a participant's eye focus deviates from the average focus of all the participants. SD closer to 0 indicates a higher level of shared attention from the participants. Figures 6-9 show the SD of the users' eye foci in each group for every frame. The tables on the right show the items that were seen by the participants. The numbers in these tables are the mean hits counts of the objects that the participants see. These numbers were acquired by detecting the collisions of the items and rays that were cast from the participants' eyes in each frame using the Unity engine's raycasting function.

The SD fluctuated ( $\min 0.084$, max 0.452, mean 0.229) most of the time and dropped for a short time (d) in Climax. The 'back (a soldier running out from a player's back)' and 'tripod (the most important moving object in the story)' were the items that were seen most by the participants in Rising Action and Climax, respectively. The interest of LIPV group is scattered quickly toward the environment.

The SD was low in the most range except for some spots in Rising Action and highly stable in Climax (min 0.048, max 0.462, mean 0.135). The 'back' was most seen by participants in Rising Action, but the number of collisions was low compared to the number of 'back' in Figure 6. During 'Rising Action', the people in this group were distracted by the falling 'meteo (meteorite)' and 'two soldiers run out of the building'.

The SD was bumpy and unstable most of the time ( $\min 0.073$, max 0.530 , mean 0.243 ), but the appearance of 'tripod' (d) captured their attention in the first part of Climax.

The SD was low and stable compared with other cases $(\min 0.064$, max 0.332, mean 0.162 ), and the tendency line goes lower as time goes by. Including the moment when the tripod was coming out from the building (d), their attention follows the moving stimulus as expected.

Although the HIPV group had only 12 participants, the results of eye gaze analysis in the climax (Figure 7) significantly demonstrates that their attention was very close and focused. In Figures 8 and 9, it is shown that the female group's concentration goes high along the story, but the male group's attention does not. The female group has a more stable attention to the story overall.

Along with the SD graphs that show the different levels of attention between the user types and genders, the elements that contributed to the participants' attention were also investigated. The following is an analysis based on the rate of eyeball collisions for each type of LIPV, HIPV, male and female in the scenes, Rising Action and Climax. Particularly, Rising Action and Climax are where the most information is delivered to the user in many media contents.

In Rising Action, one of the closest soldiers, tagged with 'back,' stopped and saw the consequence of a fallen meteorite as shown by most of the users in (a) and (b). When the soldier tagged with 'back' jumped into the scene and stopped to see what was happening at the 1150 frame in Figures 6-9, it gained a lot of attention from the HIPV and female groups as shown in (c). At frame 2300, all participants' eyes were focused on the 'tripod' which is the alien that comes out in front (d). In Climax, the participants' eyes were getting busier almost four times of the usual movement of the user's focus for the object that newly appeared in the field of view in (a) and (b). There is a considerable gap between the most focused object and others in Climax. The female group's concentration shown in Figure 9 is remarkable in both the SD graph and the collision detection from the ray of eye-gaze. 


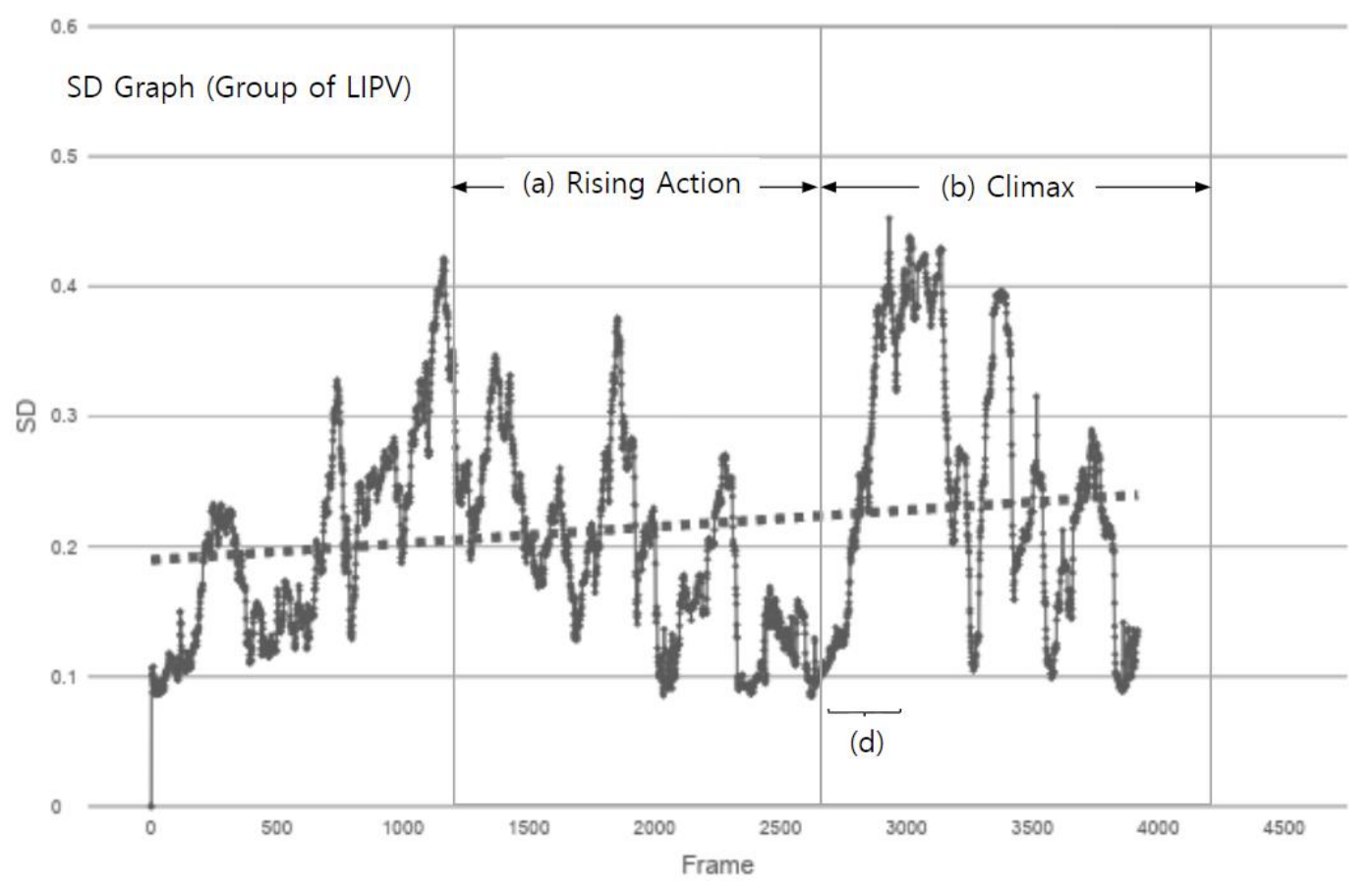

(a) Rising Action

\begin{tabular}{|l|c|}
\hline Object Name & LIPV(AVG) \\
\hline back & 131.7 \\
\hline sideblock1_1 & 63.3 \\
\hline floor & 31.5 \\
\hline block3 & 31.4 \\
\hline runner & 29.8 \\
\hline building5 & 3.7 \\
\hline pavement & 3.7 \\
\hline building2_2_3 & 3.1 \\
\hline building2_2 & 2.2 \\
\hline shooter & 2.1 \\
\hline
\end{tabular}

(b) Climax

\begin{tabular}{|l|c|}
\hline Object Name & LIPV(AVG) \\
\hline tripod & 534.3 \\
\hline shooter & 30.1 \\
\hline back & 28.4 \\
\hline sideblock1_1 & 23.3 \\
\hline runner & 15.1 \\
\hline block3 & 13.7 \\
\hline floor & 9.9 \\
\hline building4 & 6.0 \\
\hline building2_2_3 & 5.0 \\
\hline building2_2 & 3.2 \\
\hline
\end{tabular}

Figure 6. LIPV (low immersion, positive valence) group in the Rising Action and Climax (Standard Deviation (left) and Objects Most Seen (right)).

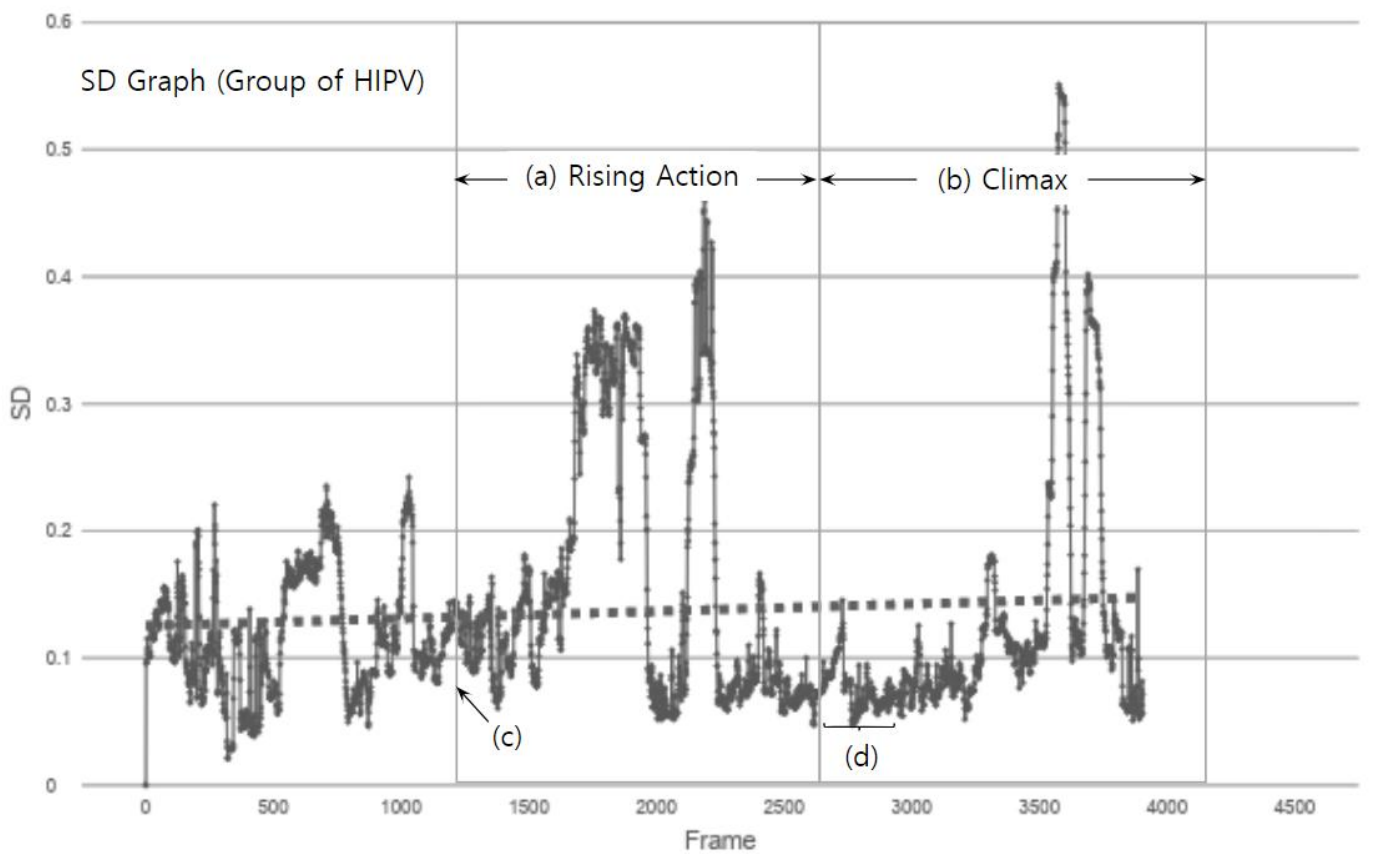

(a) Rising Action

\begin{tabular}{|l|c|}
\hline Object Name & HIPV(AVG) \\
\hline back & 98.4 \\
\hline sideblock1_1 & 44.8 \\
\hline floor & 16.9 \\
\hline block3 & 80.4 \\
\hline runner & 25.3 \\
\hline building5 & 7.2 \\
\hline pavement & 9.2 \\
\hline building2_23 & 1.1 \\
\hline building2_2 & 1.8 \\
\hline shooter & 0.7 \\
\hline
\end{tabular}

(b) Climax

\begin{tabular}{|l|c|}
\hline Object Name & HIPV(AVG) \\
\hline tripod & 471.4 \\
\hline shooter & 15.6 \\
\hline back & 20.0 \\
\hline sideblock1_1 & 25.9 \\
\hline runner & 28.9 \\
\hline block3 & 27.2 \\
\hline floor & 13.3 \\
\hline building4 & 0.3 \\
\hline building2_23 & 0.0 \\
\hline building2_2 & 1.0 \\
\hline
\end{tabular}

Figure 7. HIPV Group in the Rising Action and Climax (Standard Deviation (left) and Objects Most Seen (right)). 


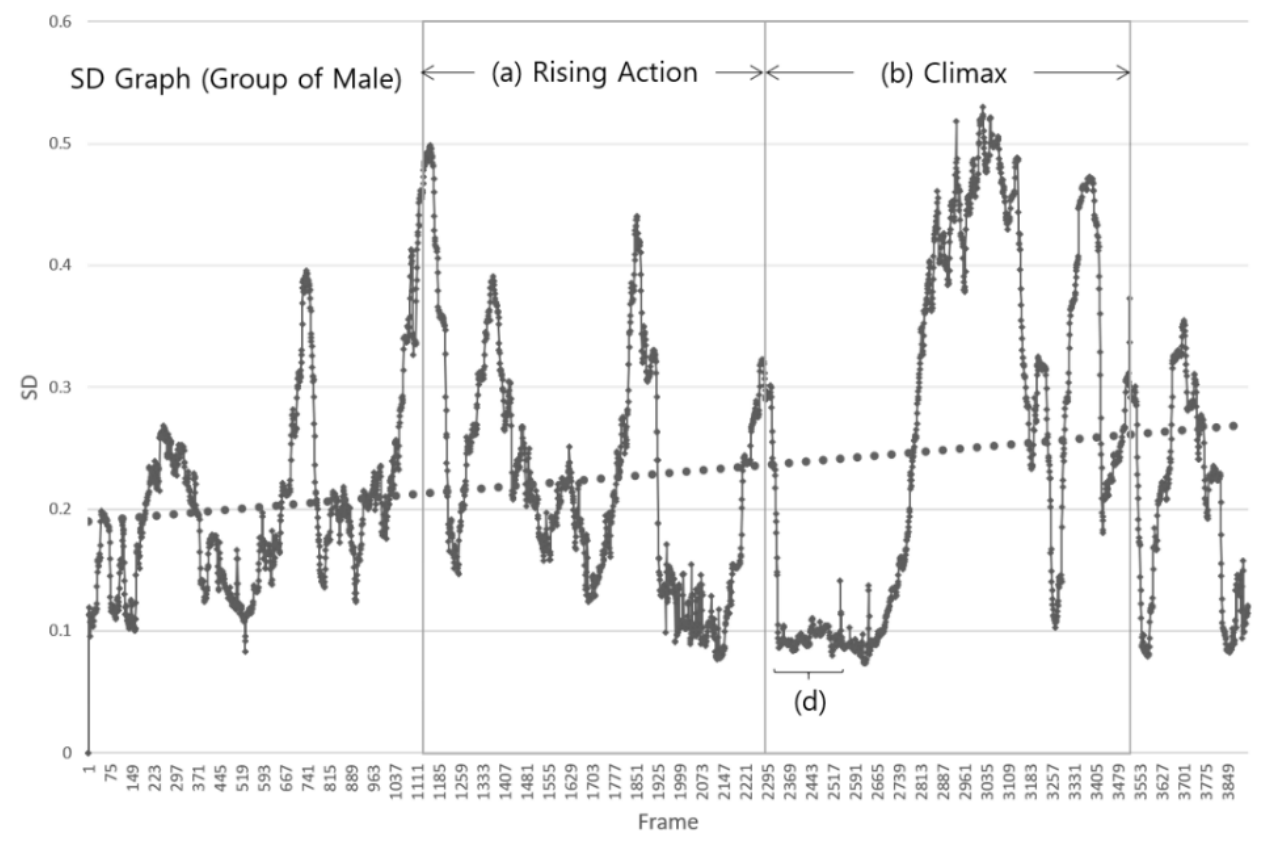

(a) Rising Action

\begin{tabular}{|l|c|}
\hline Object Name & Male(AVG) \\
\hline back & 112.0 \\
\hline sideblock1_1 & 53.5 \\
\hline floor & 32.4 \\
\hline block3 & 29.5 \\
\hline runner & 22.5 \\
\hline building5 & 5.0 \\
\hline pavement & 3.6 \\
\hline building2_2_3 & 4.0 \\
\hline building2_2 & 1.8 \\
\hline shooter & 1.3 \\
\hline
\end{tabular}

(b) Climax

\begin{tabular}{|l|c|}
\hline Object Name & Male(AVG) \\
\hline tripod & 490.5 \\
\hline shooter & 29.1 \\
\hline back & 37.2 \\
\hline sideblock1_1 & 30.1 \\
\hline runner & 18.7 \\
\hline block3 & 21.9 \\
\hline floor & 13.4 \\
\hline building4 & 8.2 \\
\hline building2_2_3 & 7.2 \\
\hline building2_2 & 4.6 \\
\hline
\end{tabular}

Figure 8. Male Group in the Rising Action and Climax (Standard Deviation (left) and Objects Most Seen (right)).

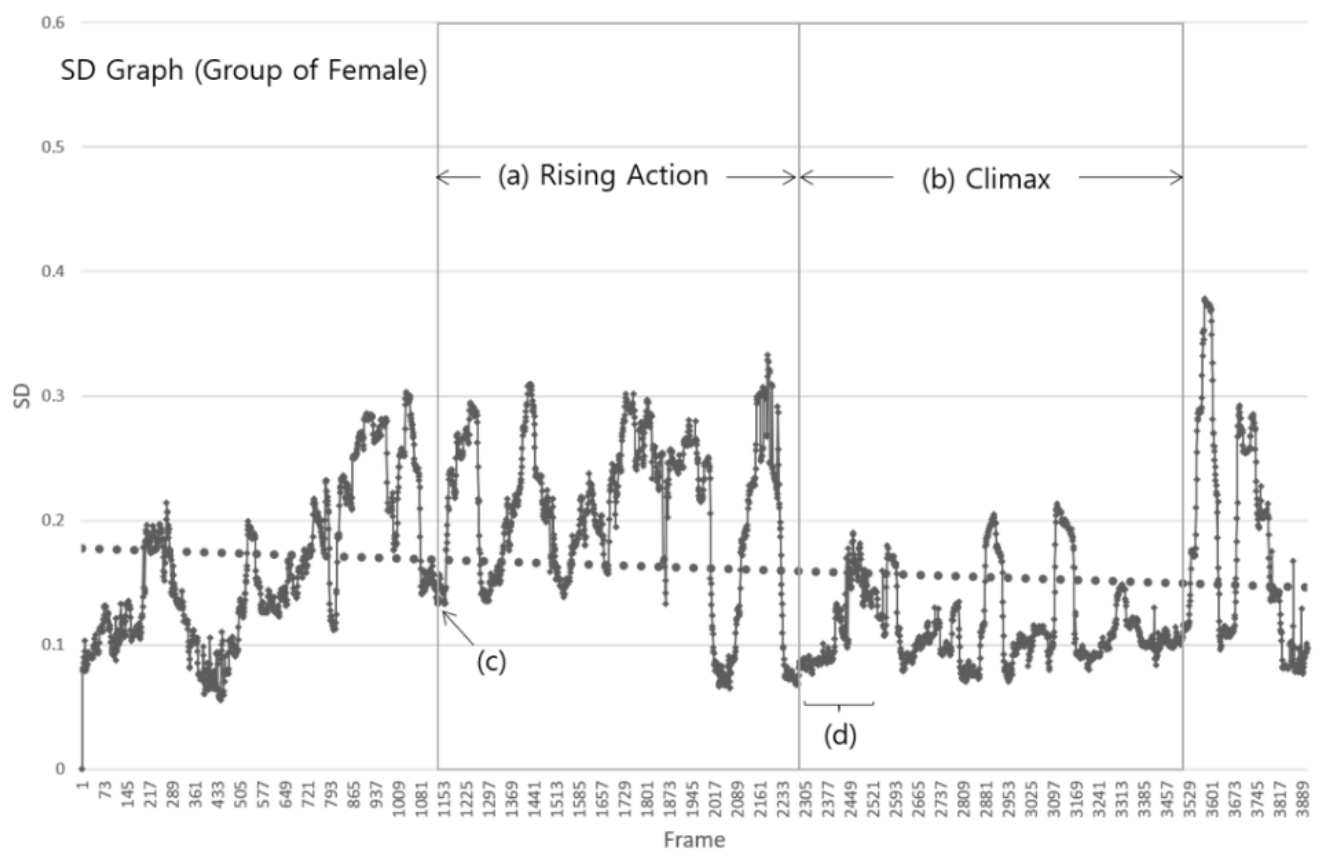

(a) Rising Action

\begin{tabular}{|l|c|}
\hline Object Name & Female(AVG) \\
\hline back & 134.6 \\
\hline sideblock1_1 & 60.9 \\
\hline floor & 21.6 \\
\hline block3 & 54.7 \\
\hline runner & 34.3 \\
\hline building5 & 3.9 \\
\hline pavement & 0.0 \\
\hline building2_2_3 & 1.0 \\
\hline building2_2 & 2.2 \\
\hline shooter & 2.3 \\
\hline
\end{tabular}

(b) Climax

\begin{tabular}{|l|c|}
\hline Object Name & Female(AVG) \\
\hline tripod & 541.9 \\
\hline shooter & 24.0 \\
\hline back & 20.2 \\
\hline sideblock1_1 & 21.0 \\
\hline runner & 21.7 \\
\hline block3 & 15.7 \\
\hline floor & 0.0 \\
\hline building4 & 0.9 \\
\hline building2_2_3 & 0.0 \\
\hline building2_2 & 0.8 \\
\hline
\end{tabular}

Figure 9. Female group in the Rising Action and Climax (Standard Deviation (left) and Objects Most Seen (right)).

\subsection{Enjoyment and Memory}

To investigate and compare the level of enjoyment, subjective answers were collected from the question '(Post-Q.1) How much did you enjoy yourself during the experience?' in the post-questionnaire. As Figure 10 suggests, all four groups of user characteristics showed similar averages, and most of the participants answered higher than ' 4 ', which corresponds to 'Agree' and 'Strongly agree', on the enjoyment level. The low immersion (LIPV) and concentration (Female) groups showed slightly higher levels of enjoyment. The male group had relatively low levels of enjoyment and high variations of SD values on each frame number. 


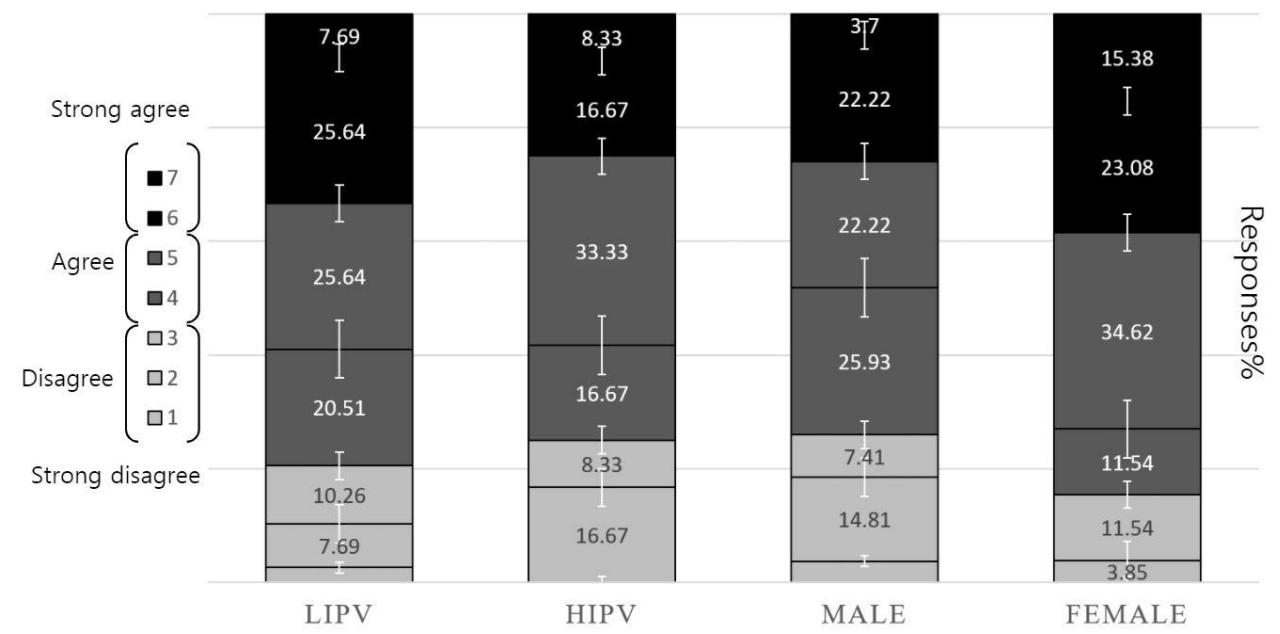

Figure 10. The level of enjoyment referred to the answers of (Post-Q.1) in post-questionnaire.

Another question regarding the participants' enjoyment was '(Post-Q.4) Did you find anything that you are interested in?' The answers in Figure 11 show the participants' willingness to remain engaged in the VR story. In particular, the HIPV and female groups had a strong willingness to remain engaged in the VR story.

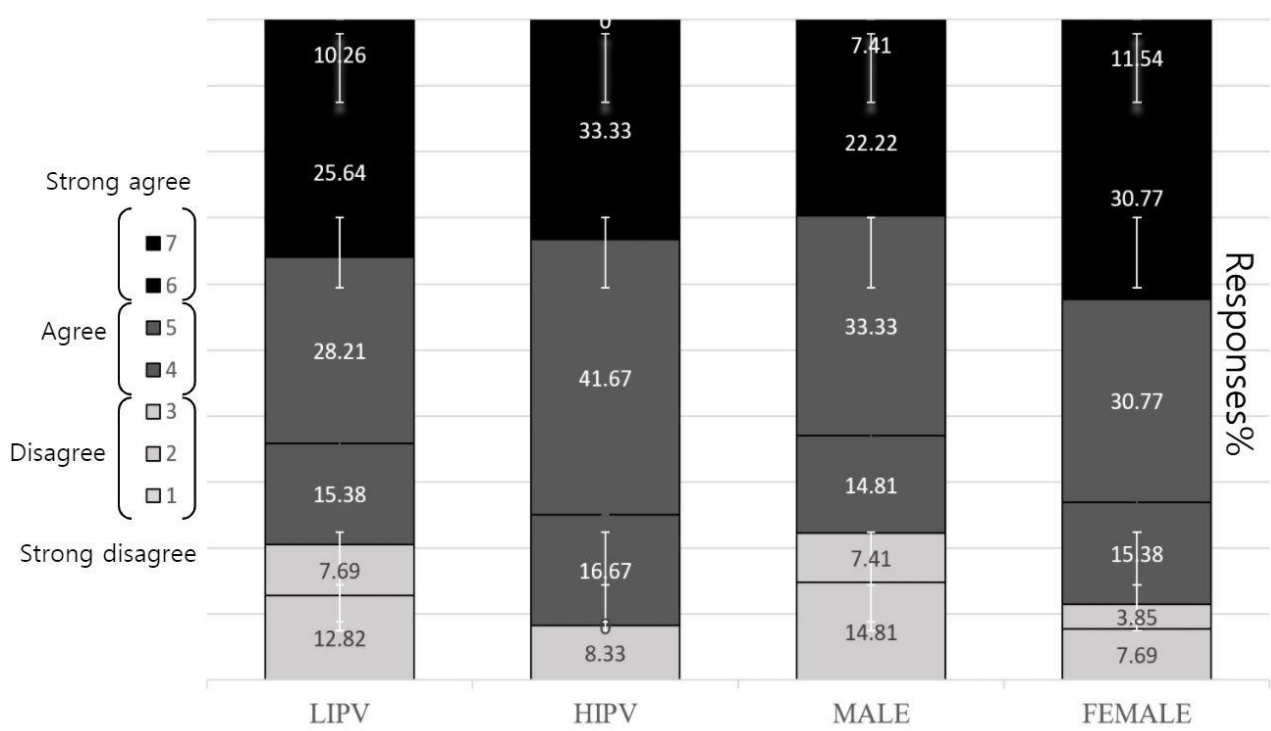

Figure 11. The level of enjoyment referred to the answers of (Post-Q.4) in post-questionnaire.

The questions about memory were '(Post-Q.6) How many soldiers were in the scene? (exclude the player)' and '(Post-Q.10) How many legs the alien has?'. (Post-Q.6) and (Post-Q.10) required simple memorization, and the soldiers and the aliens were the items that were seen the most. Figure 12 shows that the overall rate of correct answers is higher in the HIPV and female groups. In the case of the male group, the rate of correct answers for (Post-Q.6) is low compared with the other groups, but the rate for (Post-Q.10) is higher than that of the female group. 


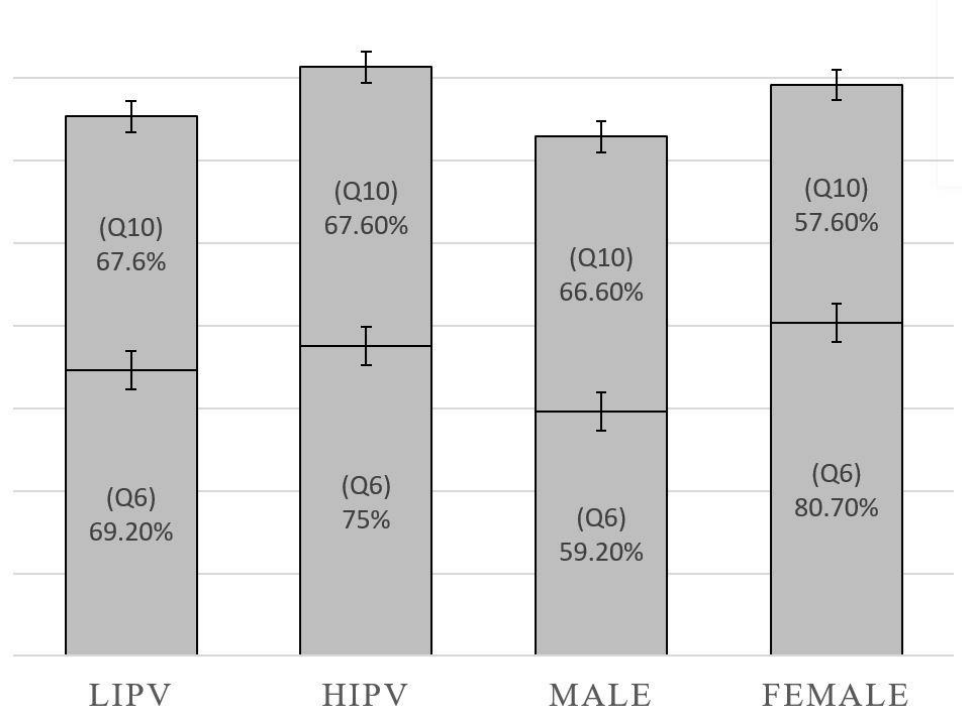

Figure 12. The rate of the right answer for the memory question referred to the answers of (Post-Q.6) and (Post-Q.10) in post-questionnaire.

Furthermore, we conducted a correlation analysis between enjoyment and memory. The results indicated no meaningful relationship between the variables (corr $=-0.132)$.

\section{Discussion}

\subsection{Summarizing the Results}

Users' level of immersion is one of crucial metrics for measuring presence, and the users' tendency for immersion is a source of presence effects [14]. With this in mind, user characteristics were classified as gender, the level of immersion, and emotional valence. Furthermore, the presence effects in VR, such as attention, enjoyment, and memory, were examined through eye-tracking and a set of questionnaires as the participants were watching a VR story. Through this experiment, we sought to answer two research questions: (1) To what extent do the user's level of immersion in prior media experiences and the emotional valence on VR affect the presence effects such as attention, enjoyment, and memory in VR? (2) To what extent does the user's gender affect the presence effects in VR? The answers to these questions are summarized as follows.

Attention following the VR story stimulus showed a low standard deviation among users with a high level of immersion in the media with positive valence and female users with high immersion in nonverbal media, just like Rotter and Rotter claimed in 1988 [34]. It means that the presence effect that responds to the stimulus and increases the attention is high. In the climax of the story's main events, most of the participants were focused on the primary objects. Enjoyment and memory, according to user characteristics, were investigated through the post-questionnaire, and the results showed a bit higher rate in the high immersion and female groups. However, the study found that higher attention groups have a bit higher levels of enjoyment and memory. In the case of enjoyment, the group with a high level of immersion in media was slightly lower than the other group but had higher interest in the VR story. Moreover, the group with high media immersion and the female group showed a high rate of correct answers overall. In the case of the male group, the rate of correct answers in a question that requires more attention was relatively higher than that of the other groups. The HIPV group, who are easily involved with media contents and focus on VR, had a higher level of presence effects.

\subsection{Relevance to Related Work}

To the best of our knowledge, the findings of our study are novel as we have not found another study that would use the same configuration of user characteristics, presence 
effects, and analysis methods. Nevertheless, the results of our study have connections to previous work as follows. De Leo et al. [24] confirmed that previous knowledge of and experiences in VR content can help increase the sense of presence among users. Our findings are, therefore, aligned with those of De Leo et al., as our study indicated that higher tendency for immersion - which is an important component in creation presenceresults in high presence effects. The results of De Leo et al. suggest that if users in the low immersion group were to be exposed to more VR content, their sense of presence-likely including also the presence effects that we explored—can increase. However, this remains to be verified in a future study.

Bulu's study [23] focused on exploring the relationships between the place presence, social presence, and co-presence in virtual worlds, discovering that the place presence has the strongest effect on user satisfaction. While this study had different focus from ours, the results can be combined with our results by designing future experiments where the virtual world is based on a place that is familiar to the user. For example, one might explore whether increased place presence can yield higher presence effects to users who are categorized to have low immersion.

Finally, Baños et al. [18] identified several user characteristics (age, gender, culture, perceptual, cognitive, motor abilities, prior experiences, willingness to suspend disbelief, and personality) that have an effect on presence effects. Out of these, out study utilized gender and prior experiences. The user's immersion in prior media experiences is a new user characteristic that differentiate our work from that of Baños et al. Moreover, Baños et al. pointed out that head-mounted-displays used for VR can have undesirable effects, such as dizziness, disorientation, and nausea, which may have an effect on the sense of presence. However, considering the recent advancements in VR technology and the fact that the study was published in 2004, we expect that the strengths of these adverse effects have significantly decreased.

\subsection{Implications of the Findings}

This study found that each user characteristics group has a different tendency for immersion. Examples of this are where a user in the group looks at or how much the user pays attention to the important objects in the scene as the story tension goes up. In the production and editing of linear media, the layout and arrangement of scenes are completed in advance. The directors have observed the audience who are familiar with linear story development by the artistic intuition and education of artists over a long period of time. However, more research is needed on whether the audience has the same attitude toward the story taking place in a virtual reality environment. This is because creating virtual reality contents needs to be customized according to this attitude in media use. This study gives content creators clues to making real-time stories in virtual reality by observing the presence effects of users, along with their characteristics (e.g., level of immersion in digital media, valence toward new media, gender, age, cultural background, and so on), and personalizing the VR experience accordingly. For instance, a story structure of a traditional media can be trans-mediated to a virtual environment, but the user experience can be different due to the different user characteristics. Therefore, content creators can utilize the results of this study in the trans-mediating process by adapting the real-time storytelling according to the presence effects experienced by the user, such as attention level.

These findings also have implications to VR system development, as they contribute toward VR experiences that are personalized based on different user characteristic groups. For example, one could create an adaptive storyline that changes its direction based on the user's characteristics, as well as their responses to the content. A suitable approach for this is machine learning based on pre-trained models for different user groups (e.g., HIPV, HINV, LIPV, LINV). However, more research and experimentation are needed before truly personalized immersion in virtual reality can become a reality. For instance, it is important to investigate the underlying reasons as to why users in the low immersion groups are less inclined to immersion; this knowledge could be used to develop methods for "training" 
the immersion ability of users and creating VR experiences that can automatically adapt to each user's current immersion level (e.g., different levels of realism, different interaction modalities, social presence, and so forth). Finally, as the VR devices become increasingly aware to the user's context (e.g., environment's geometry, eye tracking, facial expressions, physiological data), new methods for promoting immersion can be designed, such that take into account the user's context, their user characteristics and desired presence effects.

\section{Conclusions}

In this study, we performed an investigation on the relationships between user characteristics and presence effects in the context of immersive VR media. The findings of our experiment can contribute to enhancing the efficiency of the VR contents as enabler of presence in many fields. By knowing which user characteristics affect which presence effects, we can create more personalized VR experiences that take into account individual differences, thereby enhancing presence effects. Additionally, these results open new research directions on identifying optimal ways of designing VR content so that also those users with low immersion and negative valence towards VR can feel high presence, and thereby high enjoyment.

There were five limitations in this study that affect the overall impact of the results. The first limitation is that the pre-questionnaire analysis resulted in an imbalance between the user characteristic groups. The LIPV group, with relatively low levels of immersion and positive valence for virtual reality, was overwhelmingly large in comparison to other groups. If one closely observes the participants classified to have a low immersion level in this study, it is possible that they eventually have normal and healthy media usage behaviour. Another limitation is the lack of participants in the negative valence groups, HINV and LINV. The results of the study would produce different outcomes with more participants in these groups. In contrast, in the comparison between the male and female groups, the numbers of participants were fair enough to make a solid decision for the results. As the third limitation, the participants were young Korean university students; they are considered as the digital generation as they grow up in a digital environment. If we were to conduct the experiment with different age groups, such as older adults or children, or with different cultures, the results could be different. The fourth limitation is that we only used one VR scenario in the experiment as the stimulus. Other types of VR scenarios may be more appealing to some users, which may result in different levels of presence effects. The last limitation is that we considered only three user characteristics and three presence effects. To gain a deeper understanding on the relationships between user characteristics and presence effects, further research is required. In the future, we plan to develop other stimuli to support the relationships found from this research and conduct a follow-up study involving a more diverse group of participants, as well as a richer set of user characteristics and presence effects.

Author Contributions: Conceptualization, H.J.S.; formal analysis, S.J.K., H.J.S. and T.H.L.; funding acquisition, H.J.S.; investigation, H.J.S.; methodology, S.J.K.; validation, H.J.S. and T.H.L.; writingoriginal draft, S.J.K. and H.J.S.; writing-review and editing, H.J.S., S.J.K. and T.H.L. All authors have read and agreed to the published version of the manuscript.

Funding: This work was supported by the Ajou University research fund.

Institutional Review Board Statement: This research corresponds to a human subject study according to the Institutional Review Board (IRB), and it has been exempted from review since the experiment does not qualify as an invasive clinical experiment nor does it have corresponding side effects.

Informed Consent Statement: Informed consent was obtained from all subjects involved in the study.

Data Availability Statement: The data presented in this study are available on request from the corresponding author. The data are not publicly available due to the limitation of consent by the subjects. 
Acknowledgments: We thank Yoon Seok Ju and Joon Sun hang for assisting the study. We also thank Sunny Thapa Magar for assisting in editing the manuscript to the submission format.

Conflicts of Interest: The authors declare that no conflict of interest exist.

Appendix A

Table A1. Pre-questionnaire.

\begin{tabular}{|c|c|}
\hline & Yes/No \\
\hline Q.1 & Do you have any experience related to VR? \\
\hline \multicolumn{2}{|l|}{ Male/Female } \\
\hline Q.2 & What is your gender? \\
\hline \multicolumn{2}{|c|}{ Strongly disagree (1)-Strongly agree (5) } \\
\hline Q.3 & I easily become deeply involved in movies or TV dramas. \\
\hline Q.4 & I focus on a movie, so I don't recognize something occurs around me. \\
\hline Q.5 & I dive into gameplay when playing sports. \\
\hline Q.6 & I feel like I'm one of the athletes when watching a sports. \\
\hline Q.7 & I feel fear from an incident in a TV drama or a movie. \\
\hline Q.8 & I am easily immerse yourself in a movie or TV drama. \\
\hline Q.9 & If you have a virtual reality software you like, you will be immersed in it. \\
\hline Q.10 & $\begin{array}{l}\text { When virtual reality software of a preferred genre is produced, the usage bias is likely } \\
\text { to become serious. }\end{array}$ \\
\hline Q.11 & I'm not afraid of being immersed in VR. \\
\hline Q.12 & VR content must be censored before being exposed to minors. \\
\hline Q.13 & VR provides a life-like fantasy. \\
\hline Q.14 & Virtual reality gives a sense of freedom in the virtual world. \\
\hline Q.15 & We need a strict rule on a violent VR content. \\
\hline Q.16 & $\begin{array}{l}\text { We are concerned that virtual reality users will become more trapped in one's own } \\
\text { world. }\end{array}$ \\
\hline Q.17 & $\begin{array}{l}\text { With the use of virtual reality, opportunities for conversation and communication with } \\
\text { people will be reduced and personalized. }\end{array}$ \\
\hline Q.18 & VR using smart devices can make you fool. \\
\hline Q.19 & $\begin{array}{l}\text { People are likely to be confused by the problem of not being able to distinguish } \\
\text { between the virtual world and the real world by using virtual reality contents. }\end{array}$ \\
\hline Q.20 & $\begin{array}{l}\text { If celebrities, singers, and celebrities appear in virtual reality content, people will } \\
\text { likely fall into the illusion of having a more familiar relationship with them. }\end{array}$ \\
\hline Q.21 & $\begin{array}{l}\text { Even if there are side effects caused by the spread of virtual reality content, I think it is } \\
\text { worth using augmented reality content. }\end{array}$ \\
\hline Q.22 & $\begin{array}{l}\text { If you are interested, I would definitely want to experience virtual reality even if I get } \\
\text { visually tired. }\end{array}$ \\
\hline Q.23 & VR is a new opportunity to extend our experience. \\
\hline Q.24 & When a new virtual reality program comes out, I want to experience it. \\
\hline Q.25 & I don't think I need virtual reality. \\
\hline Q.26 & I don't think there is a need to use virtual reality content. \\
\hline Q.27 & Virtual reality is burdensome. \\
\hline
\end{tabular}


Table A2. Post-questionnaire.

\begin{tabular}{|c|c|}
\hline \multicolumn{2}{|r|}{ Feeling of Enjoyment } \\
\hline Q.1 & How much did you enjoy yourself during the experience? \\
\hline Q.2 & Did you find any interest in the VR content? \\
\hline Q.3 & Did you have fun? \\
\hline Q.4 & Did you find anything that you are interested in? \\
\hline Q.5 & Do you know the number of soldiers who appeared except yourself? \\
\hline \multicolumn{2}{|l|}{ Quiz for memory } \\
\hline Q.6 & How many soldiers were in the scene? \\
\hline Q.7 & Do you remember having soldiers of different colors? \\
\hline Q.8 & $\begin{array}{l}\text { What color were the soldiers of different colors? (Please answer if you selected } \\
\text { "Yes" to the above question) }\end{array}$ \\
\hline Q.9 & Do you remember how many alien legs are there? \\
\hline Q.10 & How many legs the alien has? \\
\hline Q.11 & In which direction did the first soldier come from? \\
\hline Q.12 & In which direction did the aliens come from? \\
\hline \multicolumn{2}{|l|}{ Biological questions } \\
\hline Q.13 & How old are you? \\
\hline \multicolumn{2}{|l|}{ Use of smart device } \\
\hline Q.14 & Do you have a portable multimedia device (smartphone, iPad, iPod, etc.)? \\
\hline Q.15 & Where do you usually use multimedia devices? \\
\hline Q.16 & Which program genre do you usually prefer? \\
\hline Q.17 & What is your average media time per day? \\
\hline
\end{tabular}

\section{References}

1. Melo, M.; Vasconcelos-Raposo, J.; Bessa, M. Presence and Cybersickness in Immersive Content: Effects of Content Type, Exposure Time and Gender. Comput. Graph. 2018, 71, 159-165. [CrossRef]

2. Malin, B.J. Looking White and Middle-Class: Stereoscopic Imagery and Technology in the Early Twentieth-Century United States. Q. J. Speech 2007, 93, 403-424. [CrossRef]

3. Sutherland, I.E. A Head-Mounted Three Dimensional Display. In Proceedings of the Fall Joint Computer Conference, San Francisco, CA, USA, 9-11 December 1968; p. 757.

4. Zhang, Y.; Liu, H.; Kang, S.-C.; Al-Hussein, M. Virtual Reality Applications for the Built Environment: Research Trends and Opportunities. Autom. Constr. 2020, 118, 103311. [CrossRef]

5. Duguleană, M.; Nedelcu, A.; Bărbuceanu, F. Measuring Eye Gaze Convergent Distance within Immersive Virtual Environments. Procedia Eng. 2014, 69, 333-339. [CrossRef]

6. Coelho, C.; Tichon, J.G.; Hine, T.J.; Wallis, G.M.; Riva, G. Media Presence and Inner Presence: The Sense of Presence in Virtual Reality Technologies. In From Communication to Presence: Cognition, Emotions and Culture Towards the Ultimate Communicative Experience; IOS Press: Amsterdam, The Netherlands, 2006.

7. Heeter, C. Communication Research on Consumer VR. In Communication in the Age of Virtual Reality; Lawrence Erlbaum Associates: Mahwah, NJ, USA, 1995; pp. 191-218.

8. Kim, S.; Winchester, W.; Kuc, T. The AR-CAVE: Distributed Collaborative Augmented Reality and Immersive Virtual Reality System. In Proceedings of the 3rd International Conference on Autonomous Robots and Agents, Palmerston North, New Zealand, 12-14 December 2006; pp. 351-354.

9. Zou, W.; Yang, F.; Zhang, W.; Li, Y.; Yu, H. A Framework for Assessing Spatial Presence of Omnidirectional Video on Virtual Reality Device. IEEE Access 2018, 6, 44676-44684. [CrossRef]

10. Minsky, M. Telepresence; Omni: New York, NY, USA, 1980; pp. 45-51.

11. Sheridan, T.B. Musings on Telepresence and Virtual Presence. Presence Teleoperators Virtual Environ. 1992, 1, 120-126. [CrossRef]

12. Steuer, J. Defining Virtual Reality: Dimensions Determining Telepresence. J. Commun. 1992, 42, 73-93. [CrossRef]

13. Slater, M.; Usoh, M. Representations Systems, Perceptual Position, and Presence in Immersive Virtual Environments. Presence Teleoperators Virtual Environ. 1993, 2, 221-233. [CrossRef] 
14. Witmer, B.G.; Singer, M.J. Measuring Presence in Virtual Environments: A Presence Questionnaire. Presence 1998, 7, 225-240. [CrossRef]

15. Lombard, M.; Reich, R.; Grabe, M.; Bracken, C.; Ditton, T. Presence and Television: The Role of Screen Size. Hum. Comm. Res. 2000, 26, 75-98. [CrossRef]

16. Kim, H.; Yoon, Y.P. A Study on the Subjective Typology of Stereoscopic Presence. Korean Assoc. Broadcasting Telecommun. Stud. 2010, 71, 164-204.

17. Donovan, E.; Feng, M.; Sivan, Y.Y. Issue Editors Angie Cox (Prime) Coordinating Editor Tzafnat Shpak. J. Virtual Worlds Res. 2018, $11,1-2$.

18. Baños, R.M.; Botella, C.; Alcañiz, M.; Liaño, V.; Guerrero, B.; Rey, B. Immersion and Emotion: Their Impact on the Sense of Presence. Cyberpsychology Behav. 2004, 7, 734-741. [CrossRef]

19. Jung, J.; Ahn, Y.J. Effects of Interface on Procedural Skill Transfer in Virtual Training: Lifeboat Launching Operation Study: A Comparative Assessment Interfaces in Virtual Training. Comput. Anim. Virtual Worlds 2018, 29, e1812. [CrossRef]

20. Kim, T.; Biocca, F. Telepresence via Television: Two Dimensions of Telepresence May Have Different Connections to Memory and Persuasion. J. Comput. Mediat. Commun. 2006, 3. [CrossRef]

21. Tussyadiah, I.P.; Wang, D.; Jung, T.H.; tom Dieck, M.C. Virtual Reality, Presence, and Attitude Change: Empirical Evidence from Tourism. Tour. Manag. 2018, 66, 140-154. [CrossRef]

22. Cummings, J.J.; Bailenson, J.N. How Immersive Is Enough? A Meta-Analysis of the Effect of Immersive Technology on User Presence. Media Psychol. 2016, 19, 272-309. [CrossRef]

23. Bulu, S.T. Place Presence, Social Presence, Co-Presence, and Satisfaction in Virtual Worlds. Comput. Educ. 2012, 58, 154-161. [CrossRef]

24. De Leo, G.; Diggs, L.A.; Radici, E.; Mastaglio, T.W. Measuring Sense of Presence and User Characteristics to Predict Effective Training in an Online Simulated Virtual Environment. Simul. Healthc. 2014, 9, 1-6. [CrossRef]

25. Thorens, G.; Achab, S.; Billieux, J.; Khazaal, Y.; Khan, R.; Pivin, E.; Gupta, V.; Zullino, D. Characteristics and Treatment Response of Self-Identified Problematic Internet Users in a Behavioral Addiction Outpatient Clinic. J. Behav. Addict. 2014, 3, 78-81. [CrossRef]

26. Kim, K.-S.; Sin, S.-C.J.; He, Y. Information Seeking through Social Media: Impact of User Characteristics on Social Media Use: Information Seeking through Social Media: Impact of User Characteristics on Social Media Use. Proc. Am. Soc. Info. Sci. Tech. 2013, 50, 1-4. [CrossRef]

27. Kim, J.H.; Kim, Y. Instagram User Characteristics and the Color of Their Photos: Colorfulness, Color Diversity, and Color Harmony. Inf. Process. Manag. 2019, 56, 1494-1505. [CrossRef]

28. Park, H.; Rodgers, S.; McElroy, J.A.; Everett, K. Sexual and Gender Minority's Social Media User Characteristics: Examining Preferred Health Information. Health Mark. Q. 2018, 35, 1-17. [CrossRef]

29. Central Limit Theorem. In The Concise Encyclopedia of Statistics; Springer: New York, NY, USA, 2008; pp. 66-68, ISBN 978-0387-31742-7.

30. Watts, S.; Stenner, P. Doing Q Ethodology: Theory, Method and Interpretation. Qual. Res. Psychol. 2005, 2, 67-91. [CrossRef]

31. Clay, V. Eye Tracking in Virtual Reality. J. Eye Mov. Res. 2019, 12, 1-18.

32. Hyönä, J. The Use of Eye Movements in the Study of Multimedia Learning. Learn. Instr. 2010, 20, 172-176. [CrossRef]

33. Licoppe, C.; Figeac, J. Gaze Patterns and the Temporal Organization of Multiple Activities in Mobile Smartphone Uses. Hum. Comput. Interact. 2018, 33, 311-334. [CrossRef]

34. Rotter, N.G.; Rotter, G.S. Sex Differences in the Encoding and Decoding of Negative Facial Emotions. J. Nonverbal Behav. 1988, 12, 139-148. [CrossRef] 